\title{
Randomised controlled trial of brief intervention with biofeedback and hypnotherapy in patients with refractory irritable bowel syndrome
}

\author{
${ }^{1} \mathrm{~A}$ Dobbin, ${ }^{2} \mathrm{~J}$ Dobbin, ${ }^{3} \mathrm{SC}$ Ross, ${ }^{4} \mathrm{C}$ Graham, ${ }^{5} \mathrm{MJ}$ Ford \\ ${ }^{1}$ Honorary Fellow, School of Clinical Sciences and Community Health, University of Edinburgh; ${ }^{2}$ Research Analyst, Foundation for Positive \\ Mental Health, Edinburgh; ${ }^{3}$ Clinical Hypnotherapist, Foundation for Positive Mental Health, Edinburgh; ${ }^{4}$ Statistician, Wellcome Trust \\ Clinical Research Facility, Western General Hospital, Edinburgh; ${ }^{5}$ Retired Consultant Gastroenterologist, University of Edinburgh
}

\begin{abstract}
Irritable bowel syndrome (IBS) is a common disorder associated with profoundly impaired quality of life and emotional distress. The management of refractory IBS symptoms remains challenging and non-pharmacological therapeutic approaches have been shown to be effective. We compared brief interventions with biofeedback and hypnotherapy in women referred by their GP with refractory IBS symptoms. Patients were randomised to one of two treatment groups, biofeedback or hypnotherapy, delivered as three one-hour sessions over 12 weeks. Symptom assessments were undertaken using validated, self-administered questionnaires. Two of the 128 consecutive IBS patients suitable for the study declined to consider nonpharmacological therapy and 29 patients did not attend beyond the first session. Of the 97 patients randomised into the study, 2 I failed to attend the therapy session; 15 of 76 patients who attended for therapy dropped out before week 12 post-therapy. The mean (SD) change in IBS symptom severity score 12 weeks post-treatment in the biofeedback group was -116.8 (99.3) and in the hypnotherapy group -58.0 (I0I.I), a statistically significant difference between groups (difference $=-58.8,95 \%$ confidence interval $[\mathrm{Cl}]$ for difference $[-1 \mid 1.6,-6.1], p=0.029)$. In 61 patients with refractory IBS, biofeedback and hypnotherapy were equally effective at improving IBS symptom severity scores, total non-gastrointestinal symptom scores and anxiety and depression ratings during 24 weeks follow-up. Biofeedback may prove to be the more cost-effective option as it requires less expertise.
\end{abstract}

KEYWORDS Irritable bowel syndrome, hypnotherapy, biofeedback

DECLARATION OF INTERESTS Professor Ford's institution received an endowment for this study. S Ross received a pay grant from the Leith Hospital Development Fund for work undertaken during the preparation of this study.

\section{INTRODUCTION}

Irritable bowel syndrome (IBS) is defined as abdominal pain or discomfort on three or more days each month for 12 weeks, relieved by defecation and associated with a change in stool frequency or stool appearance. ${ }^{1,2}$ Other symptoms include urgency of defecation, a sense of incomplete rectal evacuation and abdominal bloating. It is common, affecting $17 \%$ of the population, and accounts for $50 \%$ of gastroenterology outpatient workload and $5 \%$ of GP consultations. ${ }^{3,4}$ It is associated with profoundly impaired quality of life and emotional distress. ${ }^{5,6}$ Nongastrointestinal (GI) symptoms are common and fatigue and anxiety reduce quality of life more than Gl symptoms..$^{6-8}$ Patients with IBS cost twice as much in healthcare expenditure than average and have three times the likelihood of absenteeism from work. 9.10 Reducing symptom severity in IBS outpatients significantly reduces healthcare costs. ${ }^{10}$
Correspondence to A Dobbin, Foundation for Positive Mental Health, 24 Boswall Road, Edinburgh EH5 3RN, UK

tel. +44 (0)I3I 5523068
e-mail
alastair@foundationfor
positivementalhealth.com
positivementalhealth.com
The cause of IBS is unknown, although altered gastrointestinal motility, visceral hypersensitivity, hypervigilance and psychological factors have all been implicated. ${ }^{2}$ There is strong evidence of links between IBS, emotional distress and adverse life events and difficulties; ${ }^{11-13} 62 \%$ of IBS patients have an anxiety disorder $^{14}$ and anxiety and IBS have many biological factors in common. ${ }^{14}$ Studies of pain sensitivity to balloon inflation in the colon and oesophagus have shown increased pain perception with stress induction, suggesting central modulation of visceral pain perception specifically by the effect of threat. ${ }^{15,16}$ During rectosigmoidal balloon distension, functional magnetic resonance imaging ( $\mathrm{fMRI}$ ) studies show greater activation of areas regulating affective and sensory processes, including the amygdala, insula, cingulate, and prefrontal cortex in IBS patients than in control subjects. ${ }^{17,18}$ Hyperactivity of the amygdala may play an important role in the altered central processing of visceral 
information common in IBS patients. ${ }^{18-20}$ Anxiety-like behaviour and visceral hypersensitivity are associated with changes in corticotrophin releasing factor (CRF) messenger RNA (mRNA) expression in the amygdala which are inhibited by CRF receptor antagonists. ${ }^{18-20}$ There is also an interaction between oestrogen and amygdala CRF sensitivity which may, in part, explain the increased preponderance of IBS symptoms in women..$^{21,22}$ These factors suggest a possible mechanism for the co-morbidity of psychiatric disorders and IBS as well as other medically unexplained symptoms.

A healthy gastrointestinal tract is regulated by sympathetic and parasympathetic pathways of the central nervous system (CNS), mediated by their interaction with the enteric nervous system (ENS). Altered autonomic function has long been recognised in patients with IBS and is thought to contribute to the changes in visceral sensitivity and gastrointestinal motility seen in response to stress. ${ }^{23-26}$ Cardio-vagal autonomic tone, as expressed by heart rate variability (HRV) during deep breathing, is attenuated in patients with IBS compared with matched healthy control subjects, reflecting an increase in the ratio of parasympathetic to sympathetic tone. ${ }^{23}$ There is also evidence of generalised autonomic dysfunction particularly in women with IBS. ${ }^{24}$ While cardiovascular autonomic tone does not necessarily reflect changes in the autonomic control of the ENS, there is a close association between cardiac autonomic function and gastrointestinal function. ${ }^{25,26}$

Pharmacological approaches to the management of IBS have proven disappointing; meta-analyses and doubleblind controlled trials do not achieve sustained and clinically useful improvements in either symptom control or health-related quality of life. ${ }^{27}$ Non-pharmacological therapeutic approaches have therefore been studied as a way of improving symptoms. ${ }^{28,29}$ Cognitive behavioural therapy (CBT), hypnotherapy and biofeedback offer therapeutic promise in patients with refractory IBS. Gutfocused hypnotherapy has been shown to be the most effective and is now widely used throughout the UK. ${ }^{28,29}$ Hypnotherapy has major physiological effects on the autonomic nervous system within the CNS and the ENS. ${ }^{30-35}$ Hypnosis has been shown to affect HRV and peripheral skin conductance, increasing parasympathetic activity and reducing sympathetic tone. ${ }^{30-37}$

Biofeedback, CBT and relaxation training have all been well described in the management of IBS and other functional gastrointestinal disorders. ${ }^{38} 47$ Heart rate variability biofeedback (breathing retraining while monitoring changes in HRV during deep breathing) has been shown to be effective in reducing symptomatology and autonomic nervous dysfunction in hyperventilation and other functional disorders. ${ }^{42-47}$ Given the evidence of sympathovagal dysfunction in IBS patients, ${ }^{23}$ vagal tone might diminish IBS symptomatology. ${ }^{47,48}$ Though there is no direct evidence that resting vagal tone mediates changes in IBS symptoms or in work-related stress ${ }^{48}$ studies appear to support a possible role for decreased vagal tone in the evolution and maintenance of IBS symptoms. ${ }^{47-49}$

Meta-analyses of IBS treatment studies including hypnotherapy have identified substantial methodological problems with baseline measurements, inappropriately selected control groups and poorly documented or inadequate therapies for control subjects. . $^{50-52}$ Given the evidence of efficacy of hypnotherapy in IBS, we designed a trial to compare brief interventions of biofeedback with hypnotherapy. Our hypothesis was that brief intervention using HRV biofeedback would be at least as effective as gut-directed hypnotherapy in achieving significant symptomatic improvement in patients with refractory IBS.

\section{METHODS}

\section{Population}

Women aged 18-60 years referred by their general practitioner (GP) to outpatient gastroenterology clinics in the Lothian University Hospital NHS Trust were recruited. Irritable bowel syndrome was diagnosed by an experienced consultant gastroenterologist, in accordance with the Rome III criteria ${ }^{1,2}$ and after appropriate investigation. Exclusion criteria comprised a clinical history of cardiovascular, neurological, renal or endocrine disease, major psychiatric disorder or ingestion of prescribed medications known to influence cardiac autonomic tone. Patients were asked to attend every two months to be seen by one consultant gastroenterologist throughout the six month period of follow-up.

\section{Treatments}

All patients were treated along conventional lines by one clinic doctor; treatment included an explanation of the nature of IBS (verbal and written), simple advice and informal counselling together with drug therapy if required (loperamide and/or low-dose amitriptyline). Patients with refractory symptoms (no symptomatic improvement eight weeks after the initial clinic visit) were given verbal and written details of the treatments under study, and with the written agreement of patients and their general medical practitioner, randomised to one of two treatment groups: biofeedback or hypnotherapy. Block randomisation with a block size of eight was undertaken in order to achieve equal group sizes. Patients were referred to one study therapist and seen individually for three one-hour therapy sessions in the clinic during the following 12-week period.

\section{Biofeedback group}

Given the normal HRV observed during respiration, it is possible to manipulate resting cardio-sympathetic and vagal parasympathetic activity by adjusting the breathing 
rate, to identify the maximal amplitude of respiratory sinus arrhythmia (RSA) known as the resonant frequency, using methods described by Lehrer. ${ }^{49,53}$

Session I: Patients were taught to breathe using the diaphragm, placing one hand on the stomach and pushing the hand out during inspiration. Using a transducer linked to electrocardiogram (ECG) electrodes at the wrists, the ECG was relayed to a laptop computer. Fast Fourier transformation of the cardiac RR-interval data allowed the HRV to be displayed as three columns, the high frequency $[0.15-0.4 \mathrm{~Hz}]$, low frequency $[0.05-0.15 \mathrm{~Hz}]$ and very low frequency $[0.005-0.05 \mathrm{~Hz}]$ oscillations of the RR-interval reflecting levels of sympathetic and parasympathetic activity during respiration. Patients were asked to breathe for two minutes at several specific rates, ranging between four and seven breaths per minute using software to provide both a visual and auditory representation of breathing. At the end of this first session the trace was analysed to establish the breathing rate which produced the maximal respiratory sinus arrhythmia (RSA) i.e. the resonant frequency. Patients were asked to practice breathing at this rate for ten minutes, twice daily using a training CD-ROM which helped retrain their breathing to achieve optimal resting cardiac sympathetic and vagal tone.

Session 2: repeated the exercises in session I to check the breathing rate for maximising RSA; in addition, an external stressor (maths test: say the seven times table backwards) was used to show the patient the response to the stressor in real time and the recovery brought about by breathing at their resonant frequency. The patient was encouraged to focus on breathing at their optimal rate and asked to use this slow breathing technique in their everyday lives.

Session 3: focused on observing how thinking about internal stressors (a negative/worrying thought or memory) influenced breathing and autonomic function and how, when the individual breathed slowly and calmly, as they had been training themselves to do, the worrying thought was no longer (or much less) worrying.

\section{Hypnotherapy group}

Our method derived from standard hypnotic techniques ${ }^{54}$ but also incorporated gut-directed hypnotherapy imagery as described by Whorwell ${ }^{29}$ (personal communication).

Session I: introduced the patient to hypnosis, explaining the process in order to demystify it. The 25-minute hypnotic session aimed to achieve a state of calm relaxation of mind and body. Specific techniques included induction, deepening, ego-strengthening and visualisations of a healthy gut. Patients were given a 20-minute audio recording of a muscle relaxation technique to practice with once a day.
Session 2: consolidated the relaxation of session I and invited individuals to explore a possible source of their discomfort. Self-hypnosis techniques were introduced and patients were given a 20-minute audio recording to practice with at home once a day.

Session 3: focused on developing self-management through imagery-based techniques, such as metaphor work and visualisations, to reduce discomfort and anxiety.

\section{PRIMARY OUTCOME MEASURES}

Symptom assessments were undertaken at eight weeks before the start of the programme $(-8)$, at the start $(0)$, and at 12 and 24 weeks, during clinic visits, using well-validated, self-administered questionnaires: the IBS symptom severity score (IBS-SSS) $)^{55}$ comprising five visual analogue scores (VAS) of pain, distension, bowel dysfunction, quality of life and global well-being, and the Hospital Anxiety and Depression Score (HADS), ${ }^{56}$ in order to estimate the confounding influence of psychological state. In addition, patients completed VAS of non-GI symptoms (other symptoms [OS]) common in IBS patients. ${ }^{7,8}$

\section{STATISTICAL ANALYSES}

Control data were obtained from the data recorded eight weeks before the programme and at the point of entry into the study (weeks -8 and 0 ). Improvement in the IBSSSS was defined as a difference in the mean score of -30 . The original study validating the IBS-SSS confirmed that a mean change of 50 could be regarded as 'reliable improvement', while a mean change of 83 was indicative of clinically significant improvements classed as 'considerably better'. ${ }^{55}$ Our study was powered on a primary outcome comparing changes in the IBS-SSS at week 0 and 12 weeks post-treatment in the two treatment arms. Data were subsequently compared within and between the groups using two-sample paired and unpaired Student's t-tests as appropriate, together with standard multivariate tests. Using these data, it was calculated that given 30 patients per group, differences in mean IBS-SSS of 29.4 (standard deviation [SD] 40) could be detected between the groups at the $5 \%$ level with $80 \%$ power. Further statistical analyses were undertaken using a mixed model fitted using statistical analysis software (SAS) with IBS-SSS, HADS, HADS anxiety scores (HA), HADS depression scores (HD), and non-alimentary other symptoms scores as outcomes (each modelled separately with treatment and time point as fixed effects and patients as a random effect).

\section{ETHICAL APPROVAL}

All patients and their general medical practitioners participating in this study were asked for their written consent following receipt of written details of the study outline, content and purpose. This study was approved 
by the Lothian NHS Regional Ethics Committee (NREC \#06/SII04/26) and the NHS Lothian Research and Development Committee (R\&D \#2006/W/GI/05) and funded by a local medical research and development NHS endowment fund.

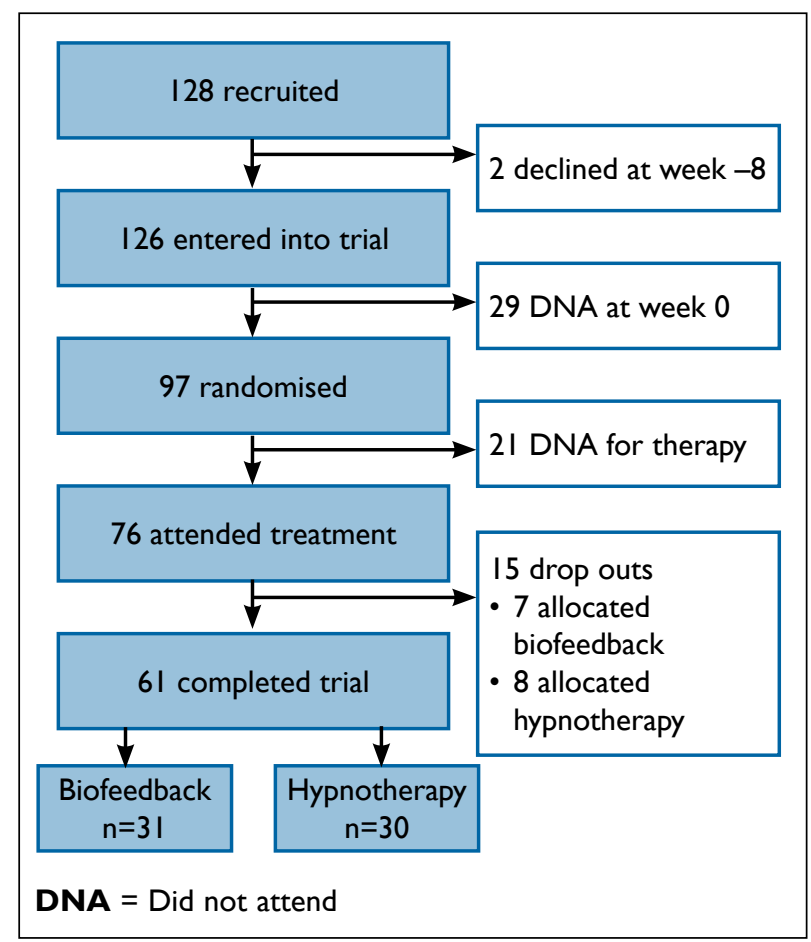

FIGURE I Recruitment flow chart.

\section{RESULTS}

Recruitment: Two of the 128 consecutive IBS patients suitable for the study declined to consider nonpharmacological therapy and 29 patients did not attend (DNA) for the first clinic review (week 0). Of 97 patients randomised into the study, $2 \mathrm{I}$ failed to attend the therapy session; 15 of 76 patients who attended for therapy dropped out before completing therapy (seven patients randomised to receive biofeedback and eight patients to hypnotherapy) (Figure I). The mean age of the study participants was $\mathbf{4 0 . 4}$ years and did not differ significantly between the two treatment groups.

Data: The following series of plots show how individual patient scores changed over time (Figures 2,4 and 5) in relation to the IBS-SSS, HADS and total OS. Time 0 was recorded at eight weeks prior to entry, time $\mathrm{I}$ at entry, time 2 at week 12 post-treatment and time 3 at week 24 post-treatment. In each plot there are two 'panels': these show the two treatment groups separately, biofeedback on the left and hypnotherapy on the right. The different colours and symbols indicate individual patients (these can be seen at www. rcpe.ac.uk/journal/issue/43-I.php).
This study was powered on a primary outcome of comparing the baseline at entry to 12 weeks posttreatment change in IBS-SS in the two treatment arms (Figure 3). The mean (SD) change in IBS-SSS from entry to 12 weeks post-treatment in the biofeedback group was -116.8 (99.3) and in the hypnotherapy group -58.0 (I0I.I), a statistically significant difference between groups (difference $=-58.8,95 \% \mathrm{Cl}$ for difference $[-|| \mid 1.6,-6.1]$, $\mathrm{p}=0.029)$. Statistical analysis of a mixed model fitted using SAS revealed modest evidence of a difference over time; however when treatment was taken into account, there was no evidence of a significant interaction between time and treatment.

Differences in IBS-SSS and HADS between week 0 and 12 weeks post-treatment are plotted in Figure 6. In order to illustrate any effect that anxiety and depression ratings may have had, the groups are represented by different symbols. Though there appears to be a relationship, from the distribution of the coloured dots, the effects are similar for both treatment groups.

\section{DISCUSSION}

This study has shown that in 61 patients with refractory IBS, the effects of hypnotherapy and biofeedback are similar and equally effective at improving symptoms. At 12 weeks, both treatments significantly improved IBSSSS, total non-GI symptom scores and anxiety and depression ratings. There was a modest difference between the two treatment groups $(p=0.029)$, but repeated measures analysis revealed a non-significant trend in favour of biofeedback $(p=0.079)$. In a previous study, mean changes in the IBS-SSS of 83 correlated with clinically significant improvements..$^{55}$ There were small but significant changes in the HAD scores (Table I); changes in psychological parameters have previously been noted as a possible confounding factor but we could not exclude the possibility that the effects of treatment could at least in part be explained by the direct effects of therapy on anxiety and depression ratings. This reduction itself could also help improve symptomatology, particularly if psychological factors play a role in triggering or exacerbating symptoms. ${ }^{50,57}$ It can be argued however, that the apparent beneficial effect of the two treatments represents a combination of specific, treatment-related effects and less specific, uncontrolled placebo effects. Apart from hypnotherapy and biofeedback, CBT is probably the most common treatment used in patients with refractory IBS. The Cochrane Collaboration suggested that CBT and interpersonal psychotherapy may be temporarily effective but it is unclear whether the effects are sustained in the longer-term. ${ }^{57}$ 


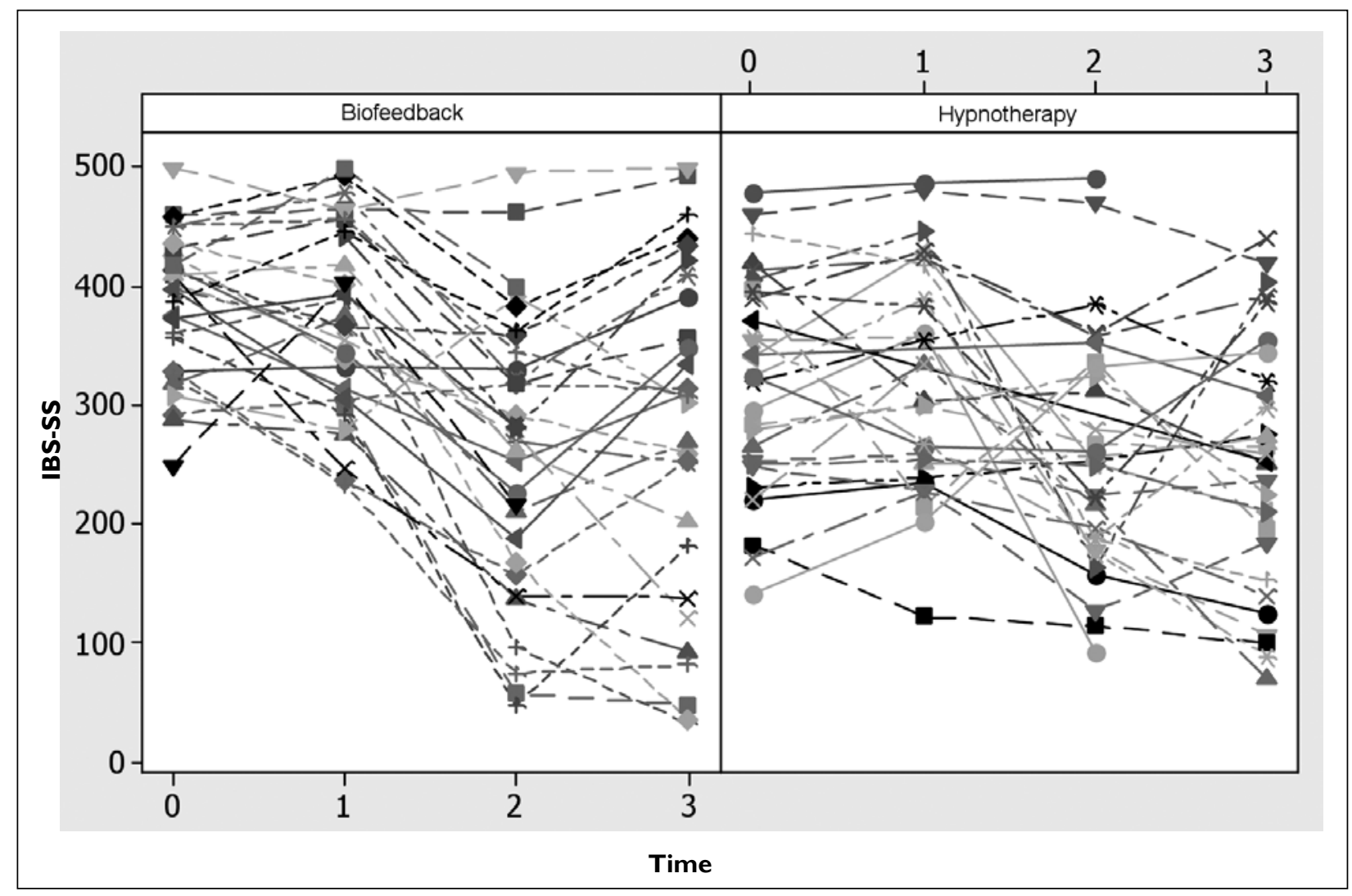

FIGURE 2A Irritable bowel syndrome symptom severity scores (IBS-SS).

\begin{tabular}{|l|c|c|c|c|}
\hline \multicolumn{5}{|l|}{ Type 3 tests of fixed effects } \\
\hline Effect & Num DF & Den DF & F value & Pr>F \\
\hline Treatment & $\mathrm{I}$ & 60 & 2.76 & 0.1020 \\
\hline Timepoint & 3 & 169 & 29.73 & $<.0001$ \\
\hline $\begin{array}{l}\text { Treatment } \\
\text { X } \\
\text { timepoint }\end{array}$ & 3 & 169 & 2.30 & 0.0791 \\
\hline $\begin{array}{l}\text { Num DF= Numerator degrees of freedom } \\
\text { Den DF= Denominator degrees of freedom } \\
\text { Pr= Probability }\end{array}$ \\
\hline
\end{tabular}

FIGURE 2B Type 3 tests of fixed effects (irritable bowel syndrome symptom severity scores).

\section{Trial design, selection bias and placebo effects}

Trials comparing psychological and other therapies in IBS are not usually double-blind and the confounding issues of patient and therapist expectancy, investigator bias, doctor-patient relationship and rapport assume major importance..$^{50-51,57-60}$ A recent study of 'warm' versus 'cold' therapists and dummy acupuncture treatment in IBS identified large placebo effects..$^{59}$ This effect in IBS therapies can be large (40-60\%). ${ }^{57-60}$ If the therapist routinely uses one of the treatments under test, an unconscious bias is likely to inflate any positive effects of that treatment and reduce treatment effects in the control group. In our study, despite exposure to only

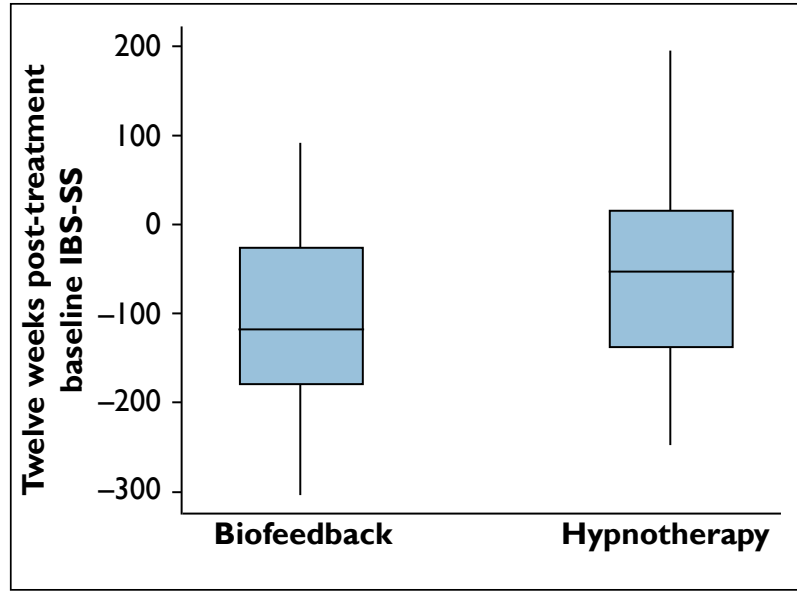

FIGURE 3 Biofeedback vs hypnotherapy (irritable bowel syndrome symptom severity scores [IBS-SS]): 12 weeks posttreatment.

one experienced gastro-enterologist with an interest in IBS and one highly-trained therapist, the drop-out rate (37\%) was significant. Studies comparing treatment efficacies should adopt an 'intention to treat' analysis, as the exclusion of any patient may significantly overestimate treatment effects. Given similar drop-out rates in the two groups and the absence of any follow-up data on drop-outs, we accepted that the only data that could be analysed were for those patients who actually attended therapy sessions. Selection bias may also occur when 


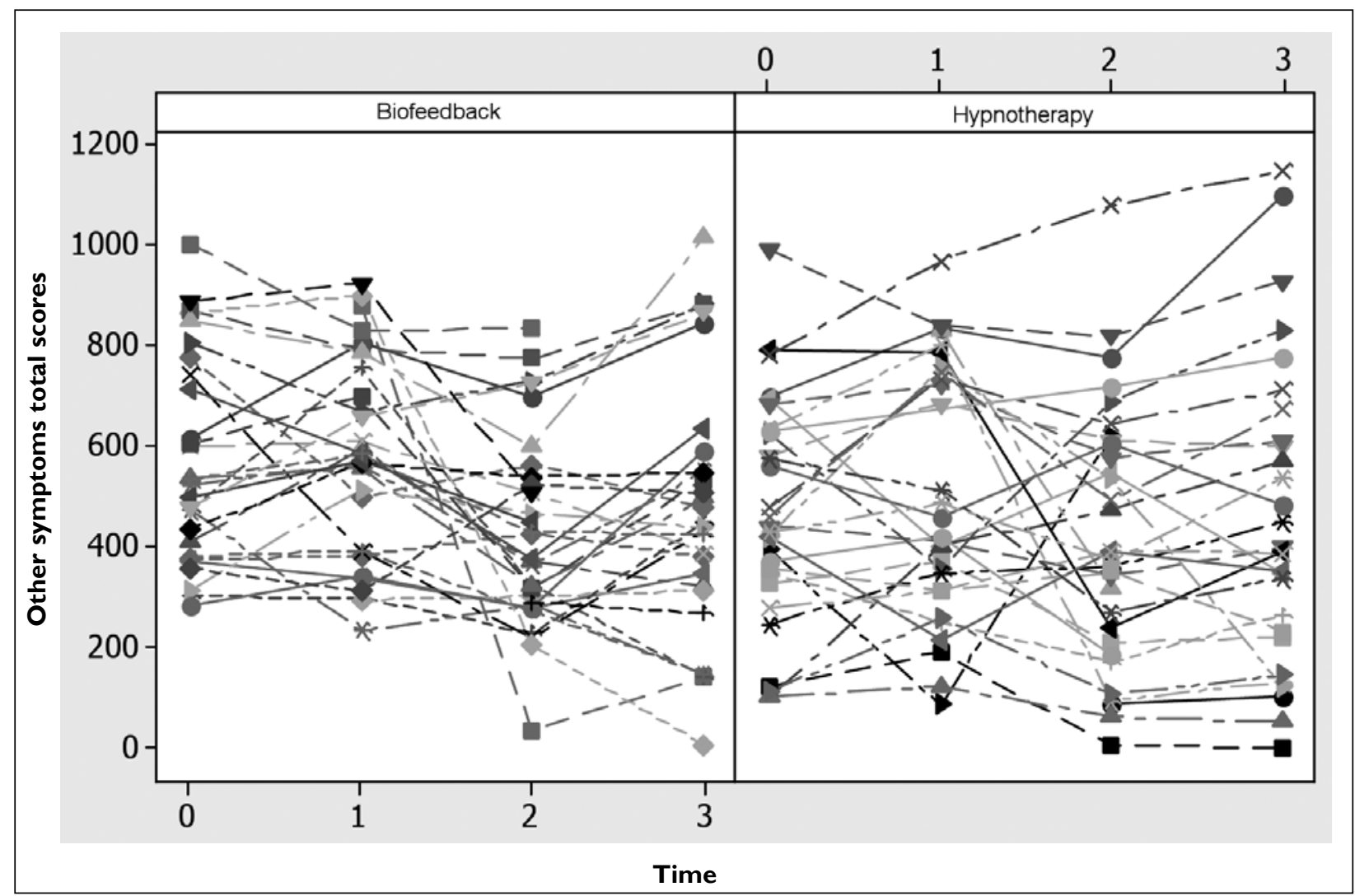

FIGURE 4A Total non-gastrointestinal symptom (other symptoms) scores.

\begin{tabular}{|l|c|c|c|c|}
\hline \multicolumn{5}{|l|}{ Type 3 tests of fixed effects } \\
\hline Effect & Num DF & Den DF & F value & Pr>F \\
\hline Treatment & $\mathrm{I}$ & 60 & 0.97 & 0.3294 \\
\hline Timepoint & 3 & 166 & 6.07 & 0.0006 \\
\hline $\begin{array}{l}\text { Treatment } \\
\text { X } \\
\text { timepoint }\end{array}$ & 3 & 166 & 1.04 & 0.3762 \\
\hline $\begin{array}{l}\text { Num DF= Numerator degrees of freedom } \\
\text { Den DF= Denominator degrees of freedom } \\
\text { Pr= Probability }\end{array}$ \\
\hline
\end{tabular}

FIGURE 4B Type 3 tests of fixed effects (other symptom scores).

patients are recruited by advertising or by direct contact with patient groups; such patient populations are very different from that obtained by random allocation from outpatient gastroenterological clinics. In the former there may be a considerable effect of self-selection on expectancy, increasing placebo effects. ${ }^{59}$ Expectancy and motivation are key components of suggestibility; ${ }^{61}$ higher patient expectancy in self-selected groups and lower motivation in hospital GI clinic groups result in significant differences in compliance, suggestibility and placebo effects. $^{62}$ Meta-analyses of randomised trials using hypnosis have recommended that future studies should employ credible therapies (i.e. behavioural or psychological) as control groups, not just waiting lists or medical treatment..$^{50-53}$ In our study the use of a therapist experienced in using both therapies under study for IBS should minimise this particular problem. Poor study design or patient selection, lack of long-term follow-up, inappropriate control groups and inattention to patient and therapist expectancy can produce unrecognised placebo effects which can inflate the apparent efficacy of specific treatments, apart from long-term follow-up, again our study design should have minised these effects. The effects of interpersonal relationships in modifying therapeutic outcomes have been well described. ${ }^{63,64}$

\section{CONCLUSION}

Biofeedback and hypnotherapy delivered by brief intervention achieved similar clinically significant improvements in refractory IBS symptoms which persisted with no additional treatment during the period 12-24 weeks. Heart rate variability biofeedback requires less training and expertise than hypnotherapy and offers economic advantages over hypnotherapy and CBT. Treatment with HRV biofeedback may therefore be a cost-effective option, avoiding patient antagonism towards psychological therapies and the potential for misunderstanding of the practice of medical hypnosis. 


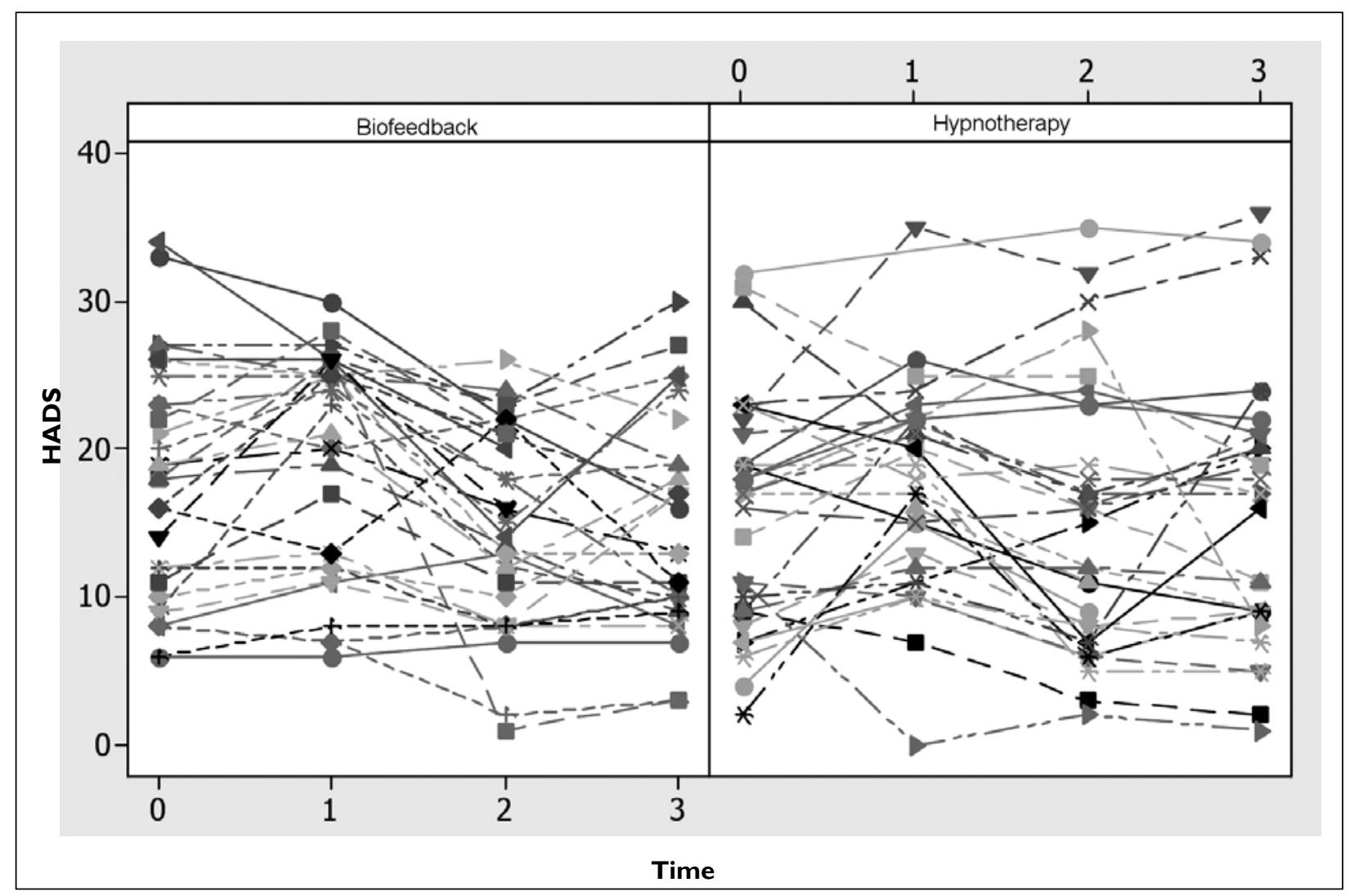

FIGURE 5A Total hospital and anxiety depression scores (HADS).

\begin{tabular}{|l|c|c|c|c|}
\hline \multicolumn{5}{|l|}{ Type 3 tests of fixed effects } \\
\hline Effect & Num DF & Den DF & F value & Pr>F \\
\hline Treatment & $\mathrm{I}$ & 60 & 0.19 & 0.6640 \\
\hline Timepoint & 3 & 172 & 9.95 & $<.000 \mathrm{I}$ \\
\hline $\begin{array}{l}\text { Treatment } \\
\text { X } \\
\text { timepoint }\end{array}$ & 3 & 172 & 1.33 & 0.2671 \\
\hline $\begin{array}{l}\text { Num DF= Numerator degrees of freedom } \\
\text { Den DF= Denominator degrees of freedom } \\
\text { Pr= Probability }\end{array}$ & & \\
\hline
\end{tabular}

FIGURE 5B Type 3 tests of fixed effects (total hospital and anxiety depression [HADS] scores).

\section{REFERENCES}

I Longstreth GF, Thompson WG, Chey WD et al. Functional bowel disorders. Gastroenterology 2006; 130:1480-91. http://dx.doi. org/10.1053/j.gastro.2005.II.061

2 Rome III:The functional gastrointestinal disorders. 3rd ed. Lawrence, Kansas: Allen Press; 2006.

3 Ferguson A, Sircus W, Eastwood MA. Frequency of 'functional' gastrointestinal disorders. Lancet 1977; 2:613-4. http://dx.doi. org/I0.10I6/S0I40-6736(77)9|466-0

4 Harvey RF, Salih SY, Read AE. Organic and functional disorders in 2000 gastroenterology outpatients. Lancet 1983; I: 632-4. http:// dx.doi.org/I0.10I6/S0I40-6736(83)91802-0

5 Halder SL, Locke GR, Talley NJ et al. Impact of functional gastrointestinal disorders on health-related quality of life: a population-based case-control study. Aliment Pharmacol Ther 2004; 19:233-42. http://dx.doi.org/I 0.I I I I/j.0269-28|3.2004.01807.x
TABLE I Hospital anxiety and depression scores

\begin{tabular}{|c|c|c|}
\hline Time period & $\begin{array}{l}\text { Biofeedback } \\
\text { Mean (SD) } \\
\text { n=3 I }\end{array}$ & $\begin{array}{l}\text { Hypnotherapy } \\
\text { Mean (SD) } \\
n=30\end{array}$ \\
\hline & $\begin{array}{l}\text { Total } \\
\text { Anxiety } \\
\text { Depression }\end{array}$ & $\begin{array}{l}\text { Total } \\
\text { Anxiety } \\
\text { Depression }\end{array}$ \\
\hline \multirow{3}{*}{$\begin{array}{l}8 \text { weeks pre- } \\
\text { treatment } \\
\text { TO }\end{array}$} & $17.8(8.0)$ & $15.7(7.9)$ \\
\hline & II.3 (4.4) & $10.0(4.9)$ \\
\hline & $6.5(4.6)$ & $5.8(4.2)$ \\
\hline \multirow{3}{*}{$\begin{array}{l}\text { At entry } \\
\text { TI }\end{array}$} & $19.6(7.4)$ & $17.5(6.9)$ \\
\hline & $12.7(4.5)$ & $11.0(4.4)$ \\
\hline & $6.9(4.1)$ & $6.6(3.4)$ \\
\hline \multirow{3}{*}{$\begin{array}{l}12 \text { weeks* post- } \\
\text { treatment } \\
\text { T2 }\end{array}$} & $14.7(6.7)$ & I5.I (8.9) \\
\hline & $9.8(4.1)$ & $9.1(5.3)$ \\
\hline & $4.9(3.7)$ & $5.9(4.9)$ \\
\hline \multirow{3}{*}{$\begin{array}{l}24 \text { weeks* post- } \\
\text { treatment } \\
\text { T3 }\end{array}$} & $14.7(7.2)$ & $15.7(9.2)$ \\
\hline & $9.6(4.0)$ & $9.2(4.8)$ \\
\hline & $5.1(4.2)$ & $6.5(5.6)$ \\
\hline \multicolumn{3}{|c|}{ "t-tests:Total hospital and anxiety depression score (HADS) } \\
\hline \multicolumn{3}{|c|}{$\begin{array}{l}\text { Biofeedback vs hypnotherapy: } \mathrm{TI} ; \mathrm{t}=\mathrm{I} . \mathrm{I} 5, \mathrm{p}=0.26 \\
\text { Biofeedback:TI vs T2; } \mathrm{t}=2.73 ; \mathrm{p}=0.008 \\
\text { Hypnotherapy:TI vs } \mathrm{T} 2 ; \mathrm{t}=\mathrm{I} . \mathrm{I} ; \mathrm{p}=0.24\end{array}$} \\
\hline
\end{tabular}


A Dobbin, J Dobbin, SC Ross, C Graham, MJ Ford

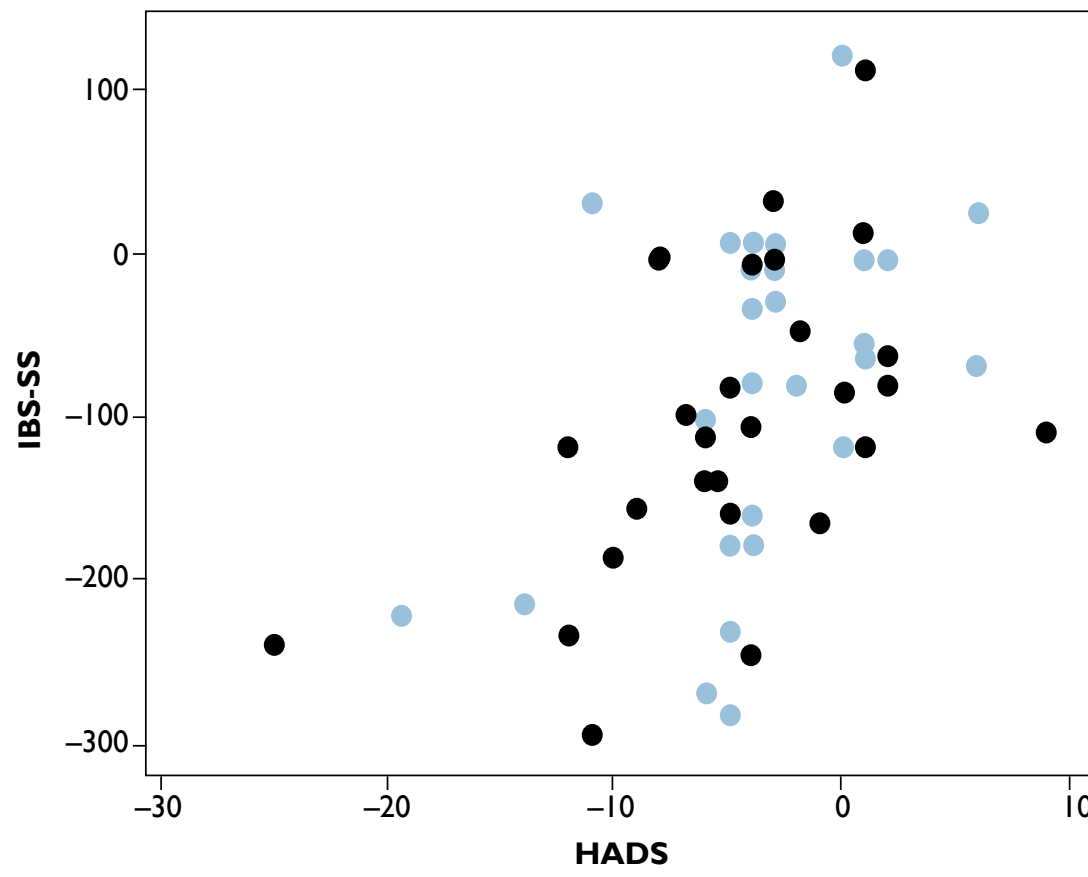

Biofeedback

- Hypnotherapy

HADS

FIGURE 6 Irritable bowel syndrome symptom severity score (IBS-SS) vs hospital anxiety and depression score (HADS).

6 Spiegel BM, Gralnek IM, Bolus R et al. Clinical determinants of health-related quality of life in patients with irritable bowel syndrome. Arch Intern Med 2004; 164:1773-80. http://dx.doi. org/10.100I/archinte.164.16.1773

7 Whorwell PJ, McCallum M, Creed FH et al. Non-colonic features of irritable bowel syndrome. Gut 1986; 27:37-40. http://dx.doi. org/10.1136/gut.27.1.37

8 Nyhlin H, Ford MJ, Eastwood J et al. Non-alimentary aspects of the irritable bowel syndrome.J Psychosom Res 1993; 37:155-62. http:// dx.doi.org// 0.1016/0022-3999(93)90082-Q

9 Drossman D, Li Z, Andruzzi E et al. US householder survey of functional gastrointestinal disorders. Prevalence, sociodemography, and health impact. Dig Dis Sci 1993; 38:1569-80. http://dx.doi. org/I0.1007/BFOI303I62

10 Talley NJ, Gabriel SE, Harmsen WS et al. Medical costs in community subjects with irritable bowel syndrome. Gastroenterology 1995 109:1736-41. http://dx.doi.org//0.1016/0016-5085(95)90738-6

II Drossman DA, Creed FH, Olden KW et al. Psychosocial aspects of the functional gastrointestinal disorders. Gut 1999; 45:1125-30. http://dx.doi.org//0.I I36/gut.45.2008.ii25

12 Ford MJ, Miller PM, Eastwood J et al. Life events, psychiatric illness and the irritable bowel syndrome. Gut 1987; 28:160-5. http://dx. doi.org/I0.1 I36/gut.28.2.160

I3 Roelofs K, Spinhoven P. Trauma and medically unexplained symptoms towards an integration of cognitive and neuro-biological accounts. Clin PsycholRev 2007;27:798-820.http://dx.doi.org//0.1016/j.cpr.2007.07.004

14 Myers B, Greenwood-Van Meerveld B. Role of anxiety in the pathophysiology of irritable bowel syndrome: importance of the amygdala. Front Neurosci 2009; 3:47. http://dx.doi.org/10.3389/ neuro.21.002.2009

15 Ford MJ, Camilleri M, Zinsmeister AR et al. Psychosensory modulation of colonic sensation in the human transverse and sigmoid colon. Gastroenterology 1995; 109:1772-80. http://dx.doi. org/10.1016/0016-5085(95)90743-2

16 Phillips ML, Gregory LJ, Cullen S et al. The effect of negative emotional context on neural and behavioural responses to oesophageal stimulation. Brain 2003; 126: 669-84. http://dx.doi. org/l0.1093/brain/awg065
17 Wilder-Smith C, Schindler D, Lovblad K et al. Brain functional magnetic resonance imaging of rectal pain and activation of endogenous inhibitory mechanisms in irritable bowel syndrome patient subgroups and healthy controls. Gut 2004; 53:1595-160I. http://dx.doi.org//0.1 I36/gut.2003.0285 I4

18 Myers B, Greenwood-Van Meerveld B. Corticosteroid receptormediated mechanisms in the amygdala regulate anxiety and colonic sensitivity. Am J Physiol Gastrointest Liver Physiol 2007; 292:G I622-9. http://dx.doi.org// 0.1 I 52/ajpgi.00080.2007

19 Myers DA, Gibson M, Schulkin J et al. Corticosterone implants to the amygdala and type I CRH receptor regulation: effects on behavior and colonic sensitivity. Behav Brain Res 2005; 161:39-44. http://dx.doi.org//0.1016/j.bbr.2005.03.001

20 Shepard JD, Myers DA. Strain differences in anxiety-like behavior: association with corticotropin-releasing factor. Behav Brain Res 2008; 186:239-45. http://dx.doi.org//0.1016/j.bbr.2007.08.013

21 Naliboff BD, Berman S, Chang L et al. Sex-related differences in IBS patients: central processing of visceral stimuli. Gastroenterology 2003;124:1738-47. http://dx.doi.org//0.1016/S0016-5085(03)00400-1

22 Weiser MJ, Handa RJ. Estrogen impairs glucocorticoid dependent negative feedback on the hypothalamic-pituitary-adrenal axis via estrogen receptor alpha within the hypothalamus. Neuroscience 2009; 159:883-95. http://dx.doi.org//0.1016/j.neuroscience.2008.12.058

23 Waring WS, Chui M, Japp A et al. Autonomic cardiovascular responses are impaired in women with irritable bowel syndrome. J Clin Gastroenterol 2004; 38:658-63. http://dx.doi.org//0.1097/0I. mcg.0000I35362.35665.49

24 Tillisch K, Mayer EA, Labus JS et al. Sex specific alterations in autonomic function among patients with irritable bowel syndrome. Gut 2005; 54:1396-40I.http://dx.doi.org//0.1 I36/gut.2004.058685

25 Buysschaert M, Donckier J, Dive A et al. Gastric acid and pancreatic polypeptide responses to sham feeding are impaired in diabetic subjects with autonomic neuropathy. Diabetes 1985; 34:1 I8I-7. http://dx.doi.org/ 0.2337/diabetes.34.I I.I I8I

26 Emmanuel AV, Kamm MA. Laser doppler flowmetry as a measure of extrinsic colonic innervation in functional bowel disease. Gut 2000; 46:2/2-7. http://dx.doi.org//0.1/36/gut.46.2.2/2 
27 Talley NJ. Pharmacologic therapy for the irritable bowel syndrome. Am J Gastroenterol 2003; 98: 750-8. http://dx.doi. org/I0.1IIII/j.1572-024I.2003.07306.x

28 Hypnotherapy for functional gastrointestinal disorders. Drug Ther Bull 2005; 43:45-8. http://dx.doi.org/I 0.I I 36/dtb.2005.43645

29 Houghton LA, Heyman DJ, Whorwell PJ. Symptomatology, quality of life and economic features of irritable bowel syndrome - the effect of hypnotherapy. Aliment Pharmacol Ther 1996; 10:91-5. http://dx.doi.org/I0.IIII/j.1365-2036.1996.tb00I8I.x

30 Rainville $P$, Hofbauer R, Bushnell $M$ et al. Hypnosis modulates activity in brain structures involved in the regulation of consciousness. J Cogn Neurosci 2002; 14:887-90I. http://dx.doi. org/I0.1I 62/08989290276019III7

31 Williamson JW, McColl R, Mathews D et al. Brain activation by central command during actual and imagined handgrip under hypnosis. J Appl Physiol 2002; 92:1317-24.

32 Beaugerie L, Burger AJ, Cadranel JF et al. Modulation of orocaecal transit time by hypnosis. Gut 199I; 32:393-4. http://dx.doi. org/ I0.1 I 36/gut.32.4.393

33 Whorwell PJ, Houghton LA, Taylor EE et al. Physiological effects of emotion: assessment via hypnosis. Lancet 1992; 340:69-72. http:// dx.doi.org/I0.1016/0140-6736(92)90394-1

34 Prior A, Whorwell PJ. Changes in rectal sensitivity after hypnotherapy in patients with irritable bowel syndrome. Gut 1990; 31:896-8. http://dx.doi.org/ I0.1 I36/gut.31.8.896

35 Houghton LA, Calvert EL, Jackson NA et al.Visceral sensation and emotion: a study using hypnosis. Gut 2002; 5 I:70I-4. http://dx.doi. org/I0.1 I36/gut.5I.5.70I

36 Lea R, Houghton LA, Calvert EL et al. Gut-focused hypnotherapy normalises disordered rectal sensitivity in patients with irritable bowel syndrome. Aliment Pharmacol Ther 2003; 17:635-42. http:// dx.doi.org/I0.1046/j.1365-2036.2003.0I486.x

37 DeBenedittis G, Cigada M, Bianchi A et al. Autonomic changes during hypnosis: a heart rate variability power spectrum analysis as a marker of sympatho-vagal balance. Int J Clin Exp Hypn 1994; 42: 140-52. http://dx.doi.org// 0.1080/00207/49408409347

38 Kellow JE, Langeluddecke PM, Eckersley GM et al. Progressive muscular relaxation and motility of the small intestine: studies in normal subjects and patients with irritable bowel syndrome. Neurogastroenterol Motil 1992; 4:47. http://dx.doi.org/I0.1 I I I/j.I365-2982.1992.tb00078.x

39 Bassotti G, Whitehead WE. Biofeedback as a treatment approach to gastrointestinal tract disorders. Amer J Gastroenterol 1994; 89: 158-64

40 Bassotti G, Whitehead WE. Biofeedback, relaxation training and cognitive behaviour modification as treatments for lower functional gastrointestinal disorders. QJM 1997; 90:545-50. http://dx.doi. org/l0.1093/qjmed/90.8.545

4I Blanchard EB. Irritable bowel syndrome: psychosocial assessment and treatment. Washington, DC: American Psychological Association; 2001. http://dx.doi.org//0.1037/10393-000

42 DeGuire S, Gevirtz R, Hawkinson D et al. Breathing retraining: a three-year follow-up study of treatment for hyperventilation syndrome and associated functional cardiac symptoms. Biofeedback Self Regul 1996; 21:191-8. http://dx.doi.org//0.1007/BF02284695

43 Gevirtz R. Resonant frequency training to restore autonomic homeostasis for treatment of psychophysiological disorders. Biofeedback 1999; 27:7-9.

44 Wilhelm FH, Gevirtz R, Roth WT. Respiratory dysregulation in anxiety, functional cardiac and pain disorders: assessment, phenomenology, and treatment. Behav Modif 200I; 25:5।3-45. http://dx.doi.org/I0.II77/0I4544550I254003

45 Del Poso J, Gevirtz R. The effect of resonant frequency cardiac biofeedback training on heart rate variability in a cardiac rehabilitation population. Appl Psychophysiol Biofeedback 2002; 27:3II.

46 Ryan M, Gevirtz R. Biofeedback-based psychophysiological treatment in a primary care setting: an initial feasibility study. Appl Psychophysiol Biofeedback 2004; 29:79-93. http://dx.doi. org/I0.1023/B:APBI.0000026635.03016.ef
47 Hjelland IE, Svebak S, Berstad A et al. Breathing exercises with vagal biofeedback may benefit patients with functional dyspepsia. Scand I Gastroenterol 2007; 42:1054-62. http://dx.doi. org/l0.1080/00365520701259208

48 Sowder E, Gevirtz R, Shapiro W et al. Restoration of vagal tone: a possible mechanism for functional abdominal pain. Appl Psychophysiol Biofeedback 2010; 35:199-206. http://dx.doi.org/I0.1007/s I0484$010-9128-8$

49 Lehrer PM,Vaschillo E,Vaschillo B. Resonant frequency biofeedback training to increase cardiac variability: rationale and manual for training. Appl Psychophysiol Biofeedback 2000; 25:177-91. http:// dx.doi.org/I0.1023/A:1009554825745

50 Talley NJ, Owen BK, Boyce P et al. Psychological treatments for irritable bowel syndrome: a critique of controlled treatment trials. Am J Gastroenterol 1996; 91:277-83.

5I Irvine EJ, Whitehead WE, Chey WD et al. Design of treatment trials for functional gastrointestinal disorders. Gastroenterology 2006; | 306: I538-51.http://dx.doi.org// 0.1053/j.gastro.2005.II.058

52 Gholamrezaei A, Ardestani SK, Emami MH. Where does hypnotherapy stand in the management of irritable bowel syndrome? A systematic review. J Altern Complement Med 2006; 12:5 17-27. http://dx.doi.org//0.1089/acm.2006.12.517

53 Song HS, Lehrer PM. The effects of specific respiratory rates on heart rate and heart rate variability. Appl Psychophysiol Biofeedback 2003; 28: 13-23. http://dx.doi.org//0.1023/A:1022312815649

54 Waxman D, editor. Hartland's medical and dental hypnosis. 3rd ed. London: Balliere Tindall; 1989.

55 Francis CY, Morris J, Whorwell PJ. The irritable bowel severity scoring system: a simple method of monitoring irritable bowel syndrome and its progress. Aliment Pharmacol Ther 1997;1 I: 395402. http://dx.doi.org/I0.1046/j.I365-2036.1997.1423/8000.x

56 Zigmond AS, Snaith RP.The hospital anxiety and depression scale. Acta Psychiatr Scand 1983; 67:361-70. http://dx.doi. org/I0.1IIII/j.1600-0447.1983.tb097/6.x

57 Zijdenbos IL, de Wit NJ, van der Heijden GJ et al. Psychological treatments for the management of irritable bowel syndrome [Internet]. Cochrane Summaries; 2009 [cited 2012 Dec 2I]. Available from: http://summaries.cochrane.org/CD006442/psychologicaltreatments-for-the-management-of-irritable-bowel-syndrome

58 Patel SM, Stason WB, Legedza $A$ et al. The placebo effect in irritable bowel syndrome trials: a meta-analysis. Neurogastroenterol Motil 2005; 17:332-40. http://dx.doi.org//0.1 I I I/j.1365-2982.2005.00650.x

59 Kaptchuk TJ, Kelley JM, Conboy LA et al. Components of the placebo effect: a randomized controlled trial in irritable bowel syndrome. BMJ 2008; 336:999-1003. http://dx.doi.org//0.1/36/ bmj.39524.439618.25

60 Enck P, Horing B, Weimer $\mathrm{K}$ et al. Placebo responses and placebo effects in functional bowel disorders. Eur J Gastroenterol Hepatol 2012; 24: I-8. http://dx.doi.org/I0.1097/MEG.0b013e32834bb95|

6I Gruzelier JH, Brow TD. Psychophysiological evidence for a state theory of hypnosis and susceptibility. J Psychosom Res 1985; 29: 287-302. http://dx.doi.org/I0.1016/0022-3999(85)90056-X

62 Liótsson B, Andersson G. Andersson E et al. Acceptability, effectiveness, and cost-effectiveness of internet-based exposure treatment for irritable bowel syndrome in a clinical sample: a randomized controlled trial. BMC Gastroenterol 20II; II:II0. http://dx.doi.org/I0.I I86/I47/-230X-II-II0

63 Elkin I, Shea MT,Watkins JT et al. National Institute of Mental Health Treatment of Depression Collaborative Research Program. General effectiveness of treatments. Arch Gen Psychiatry 1989; 46:971-82. http://dx.doi.org/I0.100I/archpsyc.1989.01810110013002

64 Blatt S, Zuroff D, Quinlan D et al. Interpersonal factors in brief treatment of depression: further analysis of the National Institute of Mental Health Treatment of Depression Collaborative Research Program. J Consult Clin Psychol 1996; 64:162-7I. http://dx.doi. org// 0.1037/0022-006X.64.1.162 